\title{
Do liberal thresholds for red cell transfusion result in improved quality of life for patients undergoing intensive chemotherapy for acute myeloid leukemia? A randomized crossover feasibility study
}

Patients with acute myeloid leukemia (AML) on intensive treatment are dependent on red blood cell (RBC) transfusion, but the evidence base defining optimal transfusion threshold support in AML is very weak. We conducted a multicenter, randomized controlled feasibility trial in patients transfused below 70 (restrictive, R) or 90g/L (liberal, L) hemoglobin. The aim of the study was to assess the feasibility of randomizing to two hemoglobin thresholds in the setting of AML and assessing quality of life (QOL) among participants. We incorporated a novel crossover design between cycles of intensive chemotherapy, thus allowing patients to serve as their own control, and assessed QoL at multiple intervals.

Patients were eligible if $\geq 18$ years, and treated with curative intent for newly diagnosed or relapsed AML, or myelodysplasia with excess of blasts (MDS-EB). Patients with prior MDS were excluded. Participants were randomized (1:1, web-based service, stratified by center) by day 5 of chemotherapy in cycle 1 , to restrictive transfusion (threshold $70 \mathrm{~g} / \mathrm{L}$; target $71-80 \mathrm{~g} / \mathrm{L}$ ) or liberal transfusion (threshold $90 \mathrm{~g} / \mathrm{L}$, target $91-100 \mathrm{~g} / \mathrm{L}$ ); participants then crossed over to the alternative policy for the second cycle

Table 1. Baseline characteristics.

\begin{tabular}{|c|c|c|c|}
\hline \multicolumn{4}{|c|}{ Baseline characteristics - N (\%) or median (q1-q3) } \\
\hline & $\begin{array}{l}\text { Restrictive then } \\
\text { liberal }(n=21)\end{array}$ & $\begin{array}{l}\text { Liberal then } \\
\text { restrictive }(n=22)\end{array}$ & Total $(n=43)$ \\
\hline Age (years) & $62(46-68)$ & $61(52-68)$ & $61(48-68)$ \\
\hline Male & $8(38)$ & $14(64)$ & $22(51)$ \\
\hline $\begin{array}{l}\text { Ethnic origin } \\
\text { Caucasian } \\
\text { Black } \\
\text { Hispanic } \\
\text { Asian }\end{array}$ & $\begin{array}{c}19(90) \\
0(0) \\
1(5) \\
1(5)\end{array}$ & $\begin{array}{l}19(86) \\
1(5) \\
0(0) \\
2(9)\end{array}$ & $\begin{aligned} 38 & (88) \\
1 & (2) \\
1 & (2) \\
3 & (7)\end{aligned}$ \\
\hline $\begin{array}{l}\text { ECOG status } \\
0 \\
1 \\
2 \\
3 \\
4\end{array}$ & $\begin{array}{l}13(62) \\
8(38) \\
0(0) \\
0(0) \\
0(0)\end{array}$ & $\begin{array}{c}13(59) \\
8(36) \\
0(0) \\
0(0) \\
1(5)\end{array}$ & $\begin{array}{c}26(60) \\
16(37) \\
0(0) \\
0(0) \\
1(2)\end{array}$ \\
\hline $\begin{array}{l}\text { Cytogenetic category } \\
\text { Not reported } \\
\text { Favorable risk } \\
\text { Standard risk } \\
\text { Poor risk }\end{array}$ & $\begin{array}{c}1(5) \\
2(10) \\
11(52) \\
7(33)\end{array}$ & $\begin{array}{c}0(0) \\
2(9) \\
14(64) \\
6(27)\end{array}$ & $\begin{array}{c}1(2) \\
4(9) \\
25(58) \\
13(30)\end{array}$ \\
\hline $\begin{array}{l}\text { AML subtype } \\
\text { First presentation } \\
\text { Relapsed }\end{array}$ & $\begin{array}{c}21(100) \\
0(0)\end{array}$ & $\begin{array}{c}20(91) \\
2(9)\end{array}$ & $\begin{array}{c}41(95) \\
2(5)\end{array}$ \\
\hline Hemoglobin (g/L) & $82(77-92)$ & $80(74-94)$ & $81(75-94)$ \\
\hline Platelets (x109/L) & $55(25-112)$ & $75(26-154)$ & $55(25-139)$ \\
\hline White cell count $\left(\times 10^{9} / \mathrm{L}\right)$ & $5(2-23)$ & $2(1-14)$ & $2(1-20)$ \\
\hline Total RBC units in 8 weeks prior to randomisation & $2(1-2)$ & $1(0-2)$ & $1(0-2)$ \\
\hline Received RBC transfusion prior to randomisation, $\mathrm{n}(\%)$ & $9(43)$ & $7(32)$ & $16(37)$ \\
\hline
\end{tabular}

ECOG: Eastern Cooperative Oncology Group Performance Status; RBC: red blood cells; q1-q3= quartile 1 to quartile 3; AML: acute myeloid leukemia. 


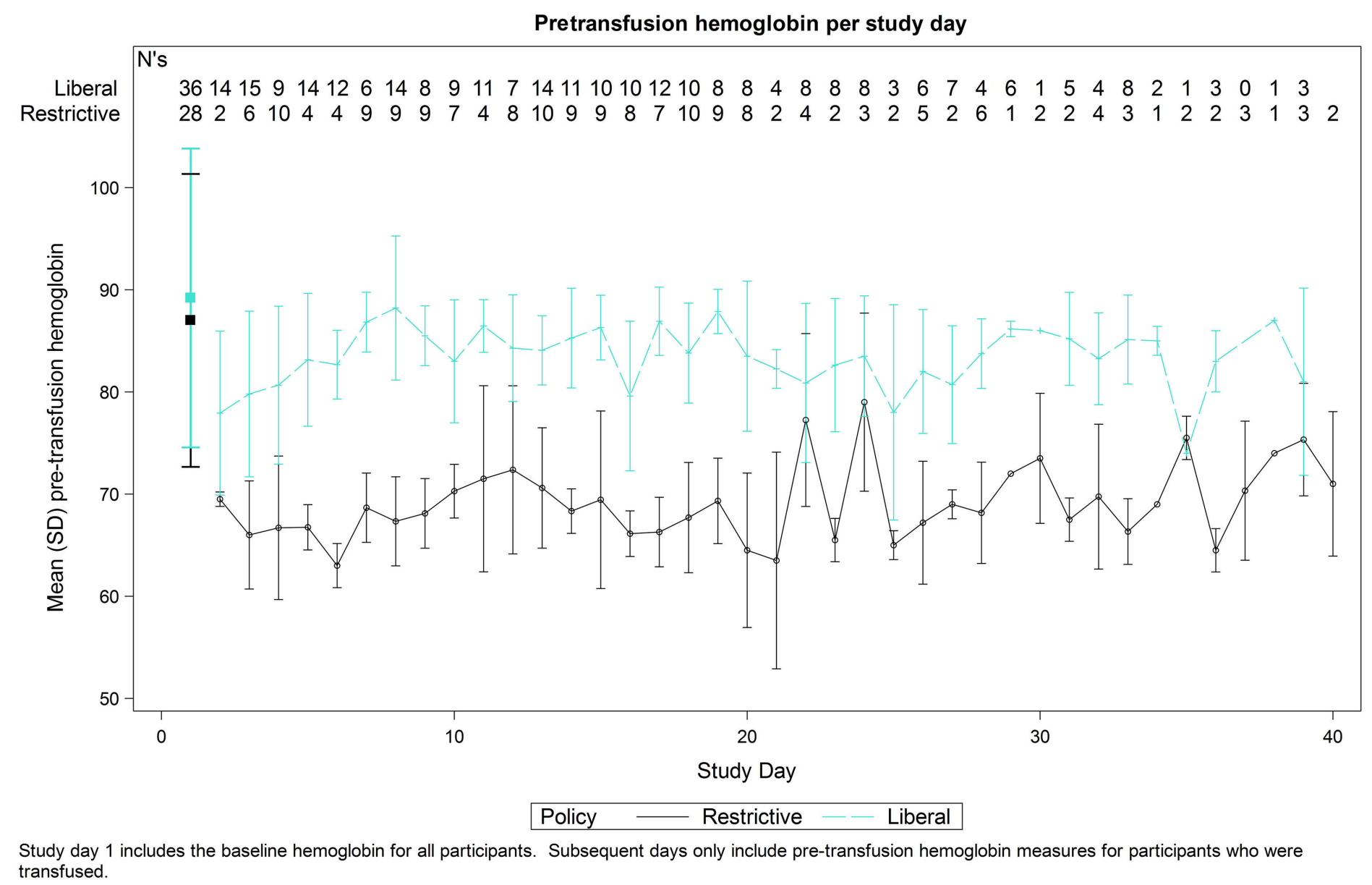

Figure 1. Pretransfusion hemoglobin.

(groups $R / L$ and $L / R$, respectively). Follow-up was until the end of the second cycle, or 42 days from start of cycle two, whichever was earlier.

Primary outcomes were: i) percentage pretransfusion hemoglobins below threshold of the assigned strategy

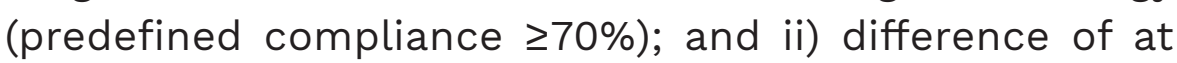
least $15 \mathrm{~g} / \mathrm{L}$ between mean pretransfusion hemoglobin in the two strategies.

Secondary outcomes included adherence to protocol and QoL; survival at 3 months; transfusion related adverse events. QoL questionnaires EORTC QLQ-C30 and EQ-5D$5 \mathrm{~L}$ were administered before, during and following each cycle. Participants also completed daily QoL scores (adapted from ECOG score ${ }^{1}$ and from EQ 5D-5 $\mathrm{L}^{2}$ ). Participants were blinded.

The sample size was 36 , based on $10 \%$ attrition and the need for 31 patients to detect 15g/L difference between the two strategies (estimated group standard deviation 20 $\mathrm{g} / \mathrm{L}, 90 \%$ power, intraclass correlation coefficient 0.25 and significance level 0.05 ; $t$-test). The analysis was intention to treat. A mixed linear regression model, with a random participant and period effect, was used to test for a difference between the groups and for evidence of a period effect. Secondary outcomes were analyzed using summary statistics. All participants completing at least one QoL questionnaire at baseline and at least one other were included in QoL analysis.

43 patients were randomized from 84 eligible (51.2\%), receiving 75 chemotherapy cycles at eight UK hospitals between May 2017 to August 2018 (Online Supplementary
Figure S1). Twenty-one participants were allocated to group R/L and 22 to group L/R. Overall, 37 participants followed the restrictive strategy and 38 the liberal strategy. Baseline characteristics were similar between the two groups (Table 1).

Pretransfusion hemoglobin was below threshold in $91 \%$ of all transfusion episodes; $77.2 \%$ for transfusions in restrictive (95\% confidence interval [Cl]: 70.7-82.8) and $99.3 \%$ in liberal (95\% Cl: 97.6-99.9) cycles. As both groups had compliance $\geq 70 \%$, this demonstrates predefined feasibility.

The unadjusted mean pretransfusion hemoglobin was 68.7 $\mathrm{g} / \mathrm{L}$ and $83.4 \mathrm{~g} / \mathrm{L}$ for the restrictive and liberal strategies respectively. After adjusting for participant as a random effect and the period effect (which was found to be significant $(P=0.01)$, with hemoglobin values lower in cycle 1 than 2$)$ the adjusted mean difference was $15.1 \mathrm{~g} / \mathrm{L}(95 \% \mathrm{Cl}$ : 13.9-16.2; $P<0.001$ ) (Figure 1). No statistically significant carry-over effect was found $(P=0.2)$.

Greater numbers of transfusions were required in the liberal arm to maintain the higher hemoglobin compared to restrictive arm. Median RBC units transfused per participant over all cycles was 13 (inter quartile range [IQR], 1017), with six units (IQR, 4-9) for the restrictive strategy and nine (IQR, 7-11) liberal. Fourteen transfusions were given for symptoms above the designated hemoglobin threshold during the restrictive strategy and none during the liberal strategy. Numbers of transfusions given according to protocol, based on hemoglobin, were 447 of 537 (83.2\%); 152 (70.7\%) for the restrictive strategy and 295 (91.6\%) liberal. 
Table 2. Secondary outcomes.

\begin{tabular}{|c|c|c|c|}
\hline & Restrictive & Liberal & Overall \\
\hline \multicolumn{4}{|l|}{ Red cell usage } \\
\hline $\begin{array}{l}\text { Transfusion episodes } \\
\text { Cycle } 1 \\
\text { Cycle } 2\end{array}$ & $\begin{array}{c}155 \\
91\end{array}$ & $\begin{array}{l}258 \\
108\end{array}$ & $\begin{array}{l}413 \\
199\end{array}$ \\
\hline Median (IQR) RBC transfused per participant & $6(4-9)$ & $9(7-11)$ & $13(10-17)$ \\
\hline $\begin{array}{l}\text { Participants with } \geq 1 \text { transfusion, } \mathrm{n} \text { (\% of all participants) } \\
\text { Cycle } 1 \\
\text { Cycle } 2\end{array}$ & $\begin{array}{c}21(100.0) \\
13(81.3)\end{array}$ & $\begin{array}{l}22(100.0) \\
16(100.0)\end{array}$ & $\begin{array}{c}43(100.0) \\
29(90.6)\end{array}$ \\
\hline RBC given as an inpatient, \% & $98.5 \%$ & $97.0 \%$ & $97.6 \%$ \\
\hline RBC given as single units, $\%$ of inpatient transfusions & $84.9 \%$ & $87.2 \%$ & $86.3 \%$ \\
\hline Number of transfusions given for symptoms & 14 & 0 & 14 \\
\hline $\begin{array}{l}\text { Median (IQR) self-evaluated health score for symptomatic transfusions } \\
\text { Prior to transfusion } \\
\text { Post transfusion }\end{array}$ & $\begin{array}{c}52(40-65) \\
55(42.5-65)\end{array}$ & - & $\begin{array}{c}52(40-65) \\
55(42.5-65)\end{array}$ \\
\hline $\begin{array}{l}\text { Median (IQR) self-evaluated health score for non-symptomatic } \\
\text { transfusions } \\
\text { Prior to transfusion } \\
\text { Post transfusion }\end{array}$ & $\begin{array}{l}55(40-75) \\
55(37-78)\end{array}$ & $\begin{array}{l}65(45-80) \\
65(45-80)\end{array}$ & $\begin{array}{l}60(42-80) \\
60(40-80)\end{array}$ \\
\hline \multicolumn{4}{|l|}{ Protocol deviations } \\
\hline Transfusions given according to hemoglobin trigger, $\mathrm{n}(\%)$ & $152(70.7 \%)$ & $295(91.6 \%)$ & $447(83.2 \%)$ \\
\hline \multicolumn{4}{|l|}{ Safety and other outcomes ${ }^{c}$} \\
\hline All cause mortality at 3 months, $\%(95 \% \mathrm{Cl})$ & - & - & $18 \%(9-34)$ \\
\hline Thrombotic events, n (\%) & $0(0.0)$ & $2(5.3)$ & $2(4.7)$ \\
\hline Grade 3 or 4 bleeding, n (\%) & $1(2.7)$ & $2(5.3)$ & $3(4.0)$ \\
\hline Syncopal events, n (\%) & $0(0.0)$ & $0(0.0)$ & $0(0.0)$ \\
\hline$\geq 1$ blood culture verified bacterial infection, $n(\%)$ & $16(43.2 \%)$ & $22(57.9 \%)$ & $27(62.8)$ \\
\hline Platelet units transfused, $\mathrm{n}$ & 298 & 369 & 667 \\
\hline Median (IQR) platelet units transfused per participant & $7(6-10)$ & $8(4-14)$ & $8(5-12)$ \\
\hline
\end{tabular}

${ }^{a}$ within 24 hours; 'bat least 24 hours, 'Serious adverse events defined as: death, life threatening adverse event, events requiring admission to hospital or prolongation of hospitalization, or resulting in significant disability, including severe sepsis, admission to intensive care unit, major organ dysfunction (single or multi-organ), transient ischemic attack, thromboembolic and ischemic events and acute transfusion reactions. RBC: red blood cells; IQR: interquartile range; Cl: confidence interval.

When the hemoglobin was below threshold, transfusions were given on 152 of 187 (81.3\%) and 295 of 447 (66.0\%) occasions for the restrictive and liberal strategies respectively.

Completion rate for QoL questionnaires was high but reduced over time; $93.0 \%$ participants completed both questionnaires at the start and $55.2 \%$ at the end. Compliance was similar for both questionnaires. Daily visual analogue scores were completed on $70.3 \%$ occasions. No clear overall correlations between daily hemoglobin and daily QoL scores were found, although in an exploratory analysis, QoL scores appeared to favor the liberal threshold in the second treatment cycle (Online Supplementary Figure S2). There was little change in the self-evaluated visual analogue score prior to and post symptom-triggered transfusion; median score 52 (IQR, 40.0-65.0) pre and 55 (IQR, 42.5-65.0) post. For non-symptomatic transfusions the score was 60 (IQR, 42-80) pre and 60 (IQR, 40-80) post (see Table 1).

Safety and other secondary outcomes are reported in Table 2. Numerically higher numbers of culture-verified infections, thrombotic events and grade 3 or 4 bleeding were seen during liberal cycles, although numbers are small.

We have previously identified the need for further trials to identify optimal transfusion support for patients with AML. ${ }^{3}$ In our study, we have successfully recruited patients with AML to follow liberal or restrictive transfusion strategies and demonstrated feasibility of a randomized crossover trial. Only two earlier small randomized trials to date have explored the impact of transfusion thresholds on outcomes in AML. A feasibility trial of patients with 
acute leukemia compared thresholds of $80 \mathrm{~g} / \mathrm{L}$ versus 120 $\mathrm{g} / \mathrm{L}$, but no QoL measures were compared, and the liberal thresholds would be considered high by current standards. ${ }^{4}$ Another small study compared $70 \mathrm{~g} / \mathrm{L}$ versus 80 $\mathrm{g} / \mathrm{L}$, but the hemoglobin differences between arms appeared too small to generate separation between arms. ${ }^{5}$ The TRIST study examined hemoglobin thresholds of 70 $\mathrm{g} / \mathrm{L}$ versus $90 \mathrm{~g} / \mathrm{L}$ in 300 patients undergoing stem cell transplantation, but the findings cannot be extrapolated to patients with AML. ${ }^{6}$

Recommendations in guidelines generally advocate for restrictive transfusion policies ${ }^{7,8,9}$ but $Q \circ L$ is a critical outcome in transfusion-dependent patients with bone marrow failure. Risks including bleeding, thrombosis and immunomodulatory effects need to be weighed against potential QoL benefits for higher hemoglobin thresholds. The numerically higher rate of culture-verified infections in patients on the liberal transfusion strategy needs to be assessed in further studies applying consistent definitions, and of note, in one previously published metaanalysis of health-care associated infection, rates were also reported to be higher in liberal transfusion threshold arms. $^{10}$

A number of additional learning points were identified that may help inform the design of further studies based on our results. We anticipated some hesitancy to consent and hence allowed 5 days from the start of treatment until randomization; $60.9 \%$ declined consent at the outset, the reasons reflecting the burden of decisions at diagnosis (Online Supplementary Table S1). Four participants declined to continue with the study after recruitment, most commonly following at least one cycle of chemotherapy, at one recruiting site, and seemingly because of a perception that the $70 \mathrm{~g} / \mathrm{L}$ threshold was too difficult to tolerate. Our study re-iterates the importance of support for clinical teams and close monitoring to support protocol adherence. Our study also supports a need for economic evaluations in larger studies. Numerically the excess transfusions in the liberal arm exceeded the two units that may have been anticipated to initially raise the hemoglobin from $70 \mathrm{~g} / \mathrm{L}$ to $90 \mathrm{~g} / \mathrm{L}$, suggesting there may be other on-going contributing factors to RBC requirements. This observation is a recurrent finding, ${ }^{11}$ and requires investigation regarding RBC loss and/or suppression of erythropoiesis when the hemoglobin is maintained at a higher level.

In summary, we have demonstrated the feasibility of randomizing to two hemoglobin thresholds in patients with AML treated with intensive chemotherapy. Given the subjectivity of QoL measurement, the ability for each participant to serve as their own control was an advantage of our study. The findings from our crossover study may be used to inform a larger definitive threshold study addressing QoL as a primary outcome.

\section{Authors}

Suzy Morton,, ${ }^{1,2}$ Mallika Sekhar, ${ }^{3,4}$ Heather Smethurst, ${ }^{5}$ Ana Mora, ${ }^{5}$ Renate L. Hodge, ${ }^{5}$ Cara L. Hudson, ${ }^{6}$ Joseph Parsons, ${ }^{6}$ Valerie Hopkins ${ }^{5}$ and Simon J. Stanworth $7,8,9$

${ }^{1}$ Department of Clinical Hematology, University Hospitals Birmingham NHS Foundation Trust, Birmingham; ${ }^{2}$ Medical Department, NHS Blood and Transplant, Birmingham; ${ }^{3}$ Department of Hematology, University College London Hospitals NHS Foundation Trust, London; ${ }^{4}$ Royal Free London NHS Foundation Trust, Department of Hematology, London; ${ }^{5}$ Clinical Trials Unit, NHS Blood and Transplant, Cambridge; ${ }^{6}$ Clinical Trials Unit, NHS Blood and Transplant, Bristol; ${ }^{7}$ Department of Clinical Hematology, Oxford University Hospitals NHS Foundation Trust, Oxford; ${ }^{8} \mathrm{Clinical}$ Department, NHS Blood and Transplant, Oxford and ${ }^{9}$ Radcliffe Department of Medicine, University of Oxford, and NIHR Oxford Biomedical Research Center, Oxford, UK

Correspondence:

SUZY MORTON - suzy.morton@nhsbt.nhs.uk https://doi.org/10.3324/haematol.2021.279867

Received: October 12, 2021.

Accepted: February 16, 2022.

Prepublished: February 24, 2022.

\section{Disclosures}

No conflicts of interest to disclose.

\section{Contributions}

SS, SM and MS designed and analyzed the study; $\mathrm{RH}$ and $\mathrm{VH}$ provided database support; $\mathrm{CH}$ and JP performed statistical analysis; HS and AM managed the trial. All authors approved the manuscript.

\section{Acknowledgments}

The authors would like to thank the hospital staff and research teams who conducted this trial and all recruited participants. Participating sites and investigators: Royal Stoke University Hospital: J. Graham; Norfolk and Norwich University Hospitals: H. Lyall; Queen Elizabeth Hospital Birmingham: S. Morton; Russells Hall Hospital: C. Taylor; Sandwell General Hospital: S. Pancham; Royal Oldham Hospital: A. Allameddine; Torbay Hospital: P. Roberts; University College Hospital London: M. Sekhar. We acknowledge A. Newland, P. White, G. Murphy (Data and Safety Monitoring Committee) and S. Knapper, J. Birchall, H. Kaur (Trial Steering Committee).

\section{Funding}

The study was supported by the NHS Blood and Transplant Clinical Trials Unit (H. Thomas, A. Deary, L. Pankhurst). The study was registered (clinicaltrials gov. Identifier: ISRCTN 96390716), received ethics approval (REC number 16/WM/0406) and adopted onto the UK's National Institute for Health Research (NIHR) Clinical Research Network Portfolio. This manuscript is independent research funded by 


\section{LETTER TO THE EDITOR}

NHS Blood and Transplant (REF15/86). The views expressed in this publication are those of the author(s) and not necessarily those of NHS Blood and Transplant.

\section{Data-sharing statement}

The datasets generated during and/or analysed during the current study will be available upon request from the NHSBT Clinical Trials Unit after de-identification (text, tables, figures and appendices) 9 months after publication and ending 5 years following article publication. Data will be shared with investigators whose use of the data has been assessed and approved by an NHSBT review committee as a methodologically sound proposal.

\section{References}

1. Buccheri G, Ferrigno D, Tamburini M. Karnofsky and ECOG performance status scoring in lung cancer: a prospective, longitudinal study of 536 patients from a single institution. Eur J Cancer. 1996;32A(7):1135-1141.

2. Devlin N, Shah K, Feng Y, Mulhern B, van Hout B. Valuing healthrelated quality of life: an EQ-5D-5L value set for England. Health Econ. 2018;27(1):7-22.

3. Loke J, Lowe DM, Miller LJ, et al. Supportive care in the management of patients with acute myeloid leukaemia: where are the research needs? Br J Haematol. 2020;190(3):311-313.

4. Webert KE, Cook RJ, Couban S, et al. A multicenter pilotrandomized controlled trial of the feasibility of an augmented red blood cell transfusion strategy for patients treated with induction chemotherapy for acute leukemia or stem cell transplantation. Transfusion. 2008;48(1):81-91.

5. DeZern AE, Williams K, Zahurak M, et al. Red blood cell transfusion triggers in acute leukemia: a randomized pilot study. Transfusion. 2016;56(7):1750-1757.

6. Tay J, Allan DS, Chatelain E, et al. Liberal versus restrictive red blood cell transfusion thresholds in hematopoietic cell transplantation: a randomized, open label, phase III, noninferiority trial. J Clin Oncol. 2020;38(13):1463-1473.

7. National Institute for Health and Care Excellence. Blood Transfusion (NICE Guideline NG24) [Internet]. 2015 [Cited 10/05/2021]. Available from https://www.nice.org.uk/guidance/ng24.

8. Carson JL, Guyatt G, Heddle NM, et al. Clinical practice guidelines from the AABB: red blood cell transfusion thresholds and storage. JAMA. 2016;316(19):2025-2035.

9. National Blood Authority Australia. The Patient Blood Management Guidelines Companions. [Internet] 2014. [Cited 10/05/2021]. Available from https://www.blood.gov.au/system/files/documents/patient_bloo d__management_guidelines_companions.pdf

10. Rohde JM, Dimcheff DE, Blumberg N, et al. Health careassociated infection after red blood cell transfusion: a systematic review and meta-analysis. JAMA. 2014;312(19):13171326.

11. Stanworth SJ, Killick S, McQuilten ZK, et al. Red cell transfusion in outpatients with myelodysplastic syndromes: a feasibility and exploratory randomised trial. $\mathrm{Br} \mathrm{J}$ Haematol. 2020;189(2):279-290. 